\title{
Microsatellite Instability Correlated Inflammatory Markers and their Prognostic Value in the Rectal Cancer Following Neoadjuvant Chemoradiotherapy: A Hypothesis-generating Study
}

\author{
JOO HO LEE ${ }^{1,2}$, BYUNG-HEE KANG ${ }^{2}$, CHANGHOON SONG $^{1}$, SUNG-BUM KANG ${ }^{3}$, \\ HYE SEUNG LEE ${ }^{4}$, KEUN-WOOK LEE ${ }^{5}$, EUI KYU CHIE ${ }^{2}$ and JAE-SUNG KIM ${ }^{1}$ \\ ${ }^{1}$ Department of Radiation Oncology, Seoul National University College of Medicine, \\ Seoul National University Bundang Hospital, Seongnam, Republic of Korea; \\ ${ }^{2}$ Department of Radiation Oncology, Seoul National University College of Medicine, \\ Seoul National University Hospital, Seoul, Republic of Korea; \\ ${ }^{3}$ Department of Surgery, Seoul National University College of Medicine, \\ Seoul National University Bundang Hospital, Seongnam, Republic of Korea; \\ ${ }^{4}$ Department of Pathology, Seoul National University College of Medicine, \\ Seoul National University Bundang Hospital, Seongnam, Republic of Korea; \\ ${ }^{5}$ Department of Internal Medicine, Seoul National University College of Medicine, \\ Seoul National University Bundang Hospital, Seongnam, Republic of Korea
}

\begin{abstract}
Background/Aim: This study aimed to analyze the correlation between microsatellite instability (MSI) and inflammatory markers during neoadjuvant CRT in rectal cancer and its influence on prognosis. Patients and Methods: A total of 549 patients with locally advanced rectal cancer underwent neoadjuvant CRT. Complete blood counts before CRT, and 4-8 weeks after CRT were used to measure neutrophil-to-lymphocyte ratio (NLR) and platelet-tolymphocyte ratio (PLR). Results: MSI was significantly associated with elevated NLR and PLR after CRT as well as with a change in NLR and PLR during CRT. Neither inflammatory markers nor MSI significantly related to survival. However, in patients with MSI, an increase in NLR
\end{abstract}

This article is freely accessible online.

Correspondence to: Jae-Sung Kim, Department of Radiation Oncology, Seoul National University College of Medicine, Seoul National University Bundang Hospital, 82 Gumi-ro 173beon-gil, Bundang-gu, Seongnam 13620, Republic of Korea. Tel: +82 317872268, e-mail: jskim@snubh.org; Eui Kyu Chie, Department of Radiation Oncology, Seoul National University College of Medicine, Seoul National University Hospital, 101 Daehak-ro, Jongno-gu, Seoul 03080, Republic of Korea. Tel: +82 220723705, e-mail: ekchie93@snu.ac.kr

Key Words: Rectal cancer, inflammatory markers, chemoradiotherapy, microsatellite instability. and PLR before CRT was significantly correlated with poor overall survival and disease-free survival. Conclusion: There is correlation between inflammatory markers and MSI during CRT and it influences prognosis. Therefore, inflammatory markers might have a role in assessing the microenvironment related to MSI and the immunologic response in rectal cancer.

Chemotherapy and radiotherapy have the potential to reprogram the tumor microenvironment and induce immunostimulatory effects, possibly by encouraging tumor antigen-specific immune response (1). In rectal cancer, neoadjuvant chemoradiotherapy (CRT) has been widely used in patients with locally advanced rectal cancer. We have previously reported that inflammatory markers including a neutrophil-to-lymphocyte ratio (NLR) and platelet-tolymphocyte ratio (PLR) can be used as a predictive marker of treatment response after neoajduvant CRT (2). In previous studies, inflammatory markers have been shown to have a direct correlation with the intra-tumoral levels of granulocyte myeloid-derived suppressor cells and regulatory $\mathrm{T}$ cells (3, 4), which can suppress anti-tumor immune reaction (1). Furthermore, the inflammatory markers have been recently found to predict the response of immunotherapy $(5,6)$.

Microsatellite instability (MSI) is one of the well-known immunologic markers in colorectal cancer, which tends to induce hyper-mutation and exhibit peri-tumoral immune cell infiltration/activation closely related to the change in tumor 
in vivo $34: 2119-2126(2020)$

Table I. Patient characteristics $(N=549)$.

\begin{tabular}{|c|c|c|c|}
\hline Factors & & $\mathrm{N}$ & $(\%)$ \\
\hline \multirow[t]{2}{*}{ Gender } & Female & 149 & 27.1 \\
\hline & Male & 400 & 73.0 \\
\hline Age, yr, median (range) & & 61 & $(28-86)$ \\
\hline \multirow[t]{2}{*}{ Distance from anal verge } & $>5 \mathrm{~cm}$ & 238 & 43.4 \\
\hline & $\leq 5 \mathrm{~cm}$ & 311 & 56.6 \\
\hline \multirow[t]{2}{*}{ CEA } & $>5 \mathrm{ng} / \mathrm{ml}$ & 388 & 70.6 \\
\hline & $\leq 5 \mathrm{ng} / \mathrm{ml}$ & 161 & 29.4 \\
\hline \multirow[t]{3}{*}{$\mathrm{cT}$} & $1-2$ & 26 & 4.7 \\
\hline & 3 & 505 & 92.0 \\
\hline & 4 & 18 & 3.3 \\
\hline \multirow[t]{2}{*}{$\mathrm{cN}$} & Negative & 78 & 14.2 \\
\hline & Positive & 471 & 85.8 \\
\hline Radiation dose & Median (range) & 50.4 & $(50.4-55.8)$ \\
\hline \multirow[t]{4}{*}{ Chemotherapy } & $5-\mathrm{FU}$ & 179 & 32.6 \\
\hline & Capecitabine & 359 & 65.4 \\
\hline & FOLFOX & 3 & 0.5 \\
\hline & Others & 8 & 1.5 \\
\hline \multirow[t]{3}{*}{ Type of surgery } & LAR & 482 & 87.8 \\
\hline & APR & 65 & 11.8 \\
\hline & Transanal excision & 2 & 0.4 \\
\hline \multirow[t]{2}{*}{ Pathology } & Adenocarcinoma & 537 & 97.8 \\
\hline & Mucinous & 12 & 2.2 \\
\hline \multirow[t]{2}{*}{ Resection margin } & Negative & 522 & 95.1 \\
\hline & Positive & 27 & 4.9 \\
\hline \multirow{2}{*}{$\begin{array}{l}\text { Tumor regression } \\
\text { grade (Dworak's) }\end{array}$} & $1-2$ & 471 & 85.8 \\
\hline & $3-4$ & 78 & 14.2 \\
\hline \multirow[t]{5}{*}{ ypT } & Tis & 19 & 3.6 \\
\hline & 1 & 29 & 5.3 \\
\hline & 2 & 153 & 28.2 \\
\hline & 3 & 338 & 62.2 \\
\hline & 4 & 4 & 0.7 \\
\hline \multirow[t]{4}{*}{ ypN } & 0 & 352 & 64.1 \\
\hline & 1 & 150 & 27.3 \\
\hline & 2 & 45 & 8.2 \\
\hline & $\mathrm{x}$ & 2 & 0.4 \\
\hline \multirow[t]{2}{*}{ LI } & Yes & 485 & 88.8 \\
\hline & No & 64 & 11.2 \\
\hline \multirow[t]{2}{*}{ VI } & Yes & 501 & 91.2 \\
\hline & No & 48 & 8.8 \\
\hline \multirow[t]{2}{*}{ PNI } & Yes & 425 & 77.4 \\
\hline & No & 124 & 22.6 \\
\hline \multirow[t]{2}{*}{ MSI } & MSI-H & 37 & 6.7 \\
\hline & MSI-L/MSS & 512 & 93.3 \\
\hline Variables & Median & & (Range) \\
\hline Pre-CRT NLR & 2.0 & & $(0.2 \sim 9.2)$ \\
\hline Post-CRT NLR & 2.9 & & $(0.9 \sim 32.0)$ \\
\hline Change of NLR & 0.46 & & $-0.74 \sim 1.30)$ \\
\hline Pre-CRT PLR & 130.7 & & 19.6 347.1) \\
\hline Post-CRT PLR & 198.8 & & $40.5 \sim 526.7)$ \\
\hline Change of PLR & 0.52 & & $-0.79 \sim 6.10)$ \\
\hline
\end{tabular}

Values in parentheses are percentages unless indicated otherwise. SD: Standard deviation; CEA: carcinoembryonic antigen; 3D-CRT: threedimension conformal radiotherapy; Gy: gray; LAR: low anterior resection; APR: abdominoperineal resection; ULAR: ultra-low anterior resection; LI: lymphatic invasion; VI: venous invasion; PNI: perineural invasion; NLR: Neutrophil to lymphocyte ratio; MSI: microsatellite instability; MSI-H: high-degree microsatellite instability; MSI-L: lowdegree microsatellite instability; MSS: microsatellite stability; CRT: chemoradiotherapy; NLR: neutrophil-to-lymphocyte ratio; PLR: platelet-to-lymphocyte ratio.
Table II. Comparison of clinical factors between MSS vs. MSI.

\begin{tabular}{|c|c|c|c|}
\hline Factor & $\begin{array}{c}\text { MSS } \\
\mathrm{N}=512\end{array}$ & $\begin{array}{c}\text { MSI } \\
\mathrm{N}=37\end{array}$ & $p$-Value \\
\hline \multicolumn{4}{|l|}{ Age } \\
\hline$\leq 60$ & $244(47.7 \%)$ & $17(45.9 \%)$ & 0.840 \\
\hline$>60$ & $268(52.3 \%)$ & $20(54.1 \%)$ & \\
\hline \multicolumn{4}{|l|}{ Gender } \\
\hline Female & $137(26.8 \%)$ & $12(32.4 \%)$ & 0.450 \\
\hline Male & $375(73.2 \%)$ & $25(67.6 \%)$ & \\
\hline \multicolumn{4}{|l|}{$\mathrm{AV}$} \\
\hline$\geq 5 \mathrm{~cm}$ & $228(44.5 \%)$ & $10(27.0 \%)$ & 0.060 \\
\hline$<5 \mathrm{~cm}$ & $284(55.5 \%)$ & $27(73.0 \%)$ & \\
\hline \multicolumn{4}{|l|}{$\mathrm{cT}$} \\
\hline $\mathrm{T} 1-2$ & $25(4.9 \%)$ & $1(2.7 \%)$ & 0.430 \\
\hline $\mathrm{T} 3$ & $469(91.6 \%)$ & $36(97.3 \%)$ & \\
\hline $\mathrm{T} 4$ & $18(3.5 \%)$ & $0(0.0 \%)$ & \\
\hline \multicolumn{4}{|c|}{ Clinical node involvement } \\
\hline Negative & $73(14.3 \%)$ & $5(13.9 \%)$ & 0.900 \\
\hline Positive & $439(85.7 \%)$ & $32(86.5 \%)$ & \\
\hline \multicolumn{4}{|l|}{ CEA } \\
\hline$>5 \mathrm{ng} / \mathrm{ml}$ & $361(70.5)$ & $27(73.0)$ & 0.830 \\
\hline$\leq 5 \mathrm{ng} / \mathrm{ml}$ & $151(29.5)$ & $10(27.0)$ & \\
\hline \multicolumn{4}{|l|}{ Surgery } \\
\hline LAR & $446(87.0 \%)$ & $32(87.0 \%)$ & 0.200 \\
\hline APR & $64(12.3 \%)$ & $5(13.0 \%)$ & \\
\hline TAE & $2(0.7 \%)$ & $0(0.0 \%)$ & \\
\hline \multicolumn{4}{|l|}{ Pathology } \\
\hline Adenocarcinoma & $501(97.9 \%)$ & $35(94.7 \%)$ & 0.470 \\
\hline Etc & $11(2.1 \%)$ & $2(5.4 \%)$ & \\
\hline \multicolumn{4}{|l|}{ Resection margin } \\
\hline Negative & $489(95.5 \%)$ & $33(91.7 \%)$ & 0.290 \\
\hline Positive & $23(4.5 \%)$ & $4(10.8 \%)$ & \\
\hline \multicolumn{4}{|c|}{ Tumor regression grade } \\
\hline $1-2$ & $440(85.9 \%)$ & $28(75.7 \%)$ & 0.089 \\
\hline $3-4$ & $72(14.1 \%)$ & $9(24.3 \%)$ & \\
\hline \multicolumn{4}{|l|}{ Lymphatic invasion } \\
\hline No & $453(88.5 \%)$ & $33(89.2 \%)$ & 0.940 \\
\hline Yes & $59(11.5 \%)$ & $4(10.8 \%)$ & \\
\hline \multicolumn{4}{|l|}{ Vascular invasion } \\
\hline No & $468(91.4 \%)$ & $34(91.9 \%)$ & 0.920 \\
\hline Yes & $44(8.6 \%)$ & $3(8.1 \%)$ & \\
\hline \multicolumn{4}{|l|}{ Perineural invasion } \\
\hline No & $398(77.7 \%)$ & $27(73.0 \%)$ & 0.510 \\
\hline Yes & $114(22.3 \%)$ & $10(27.0 \%)$ & \\
\hline \multicolumn{4}{|l|}{ ypT } \\
\hline $0-2$ & $183(35.6 \%)$ & $16(43.2 \%)$ & 0.360 \\
\hline $3-4$ & $329(64.4 \%)$ & $21(55.8 \%)$ & \\
\hline \multicolumn{4}{|l|}{ ypN } \\
\hline Negative & $382(74.6 \%)$ & $27(73.0 \%)$ & 0.800 \\
\hline Positive & $130(25.4 \%)$ & $10(27.0 \%)$ & \\
\hline $\begin{array}{l}\text { Inflammatory } \\
\text { markers }\end{array}$ & $\begin{array}{l}\text { MSS, median } \\
\quad \text { (range) }\end{array}$ & $\begin{array}{l}\text { MSI, median } \\
\quad \text { (range) }\end{array}$ & \\
\hline Pre-CRT NLR & $2.0(0.2 \sim 9.2)$ & $1.9(0.9 \sim 4.9)$ & 0.590 \\
\hline Post-CRT NLR & $2.9(0.9 \sim 32.1)$ & $3.7(1.3 \sim 15.2)$ & 0.004 \\
\hline Change of NLR & $0.44(-0.7 \sim 1.301)$ & $0.68(-0.24 \sim 7.87)$ & 0.011 \\
\hline Pre-CRT PLR & $132.1(19.6 \sim 347.1)$ & $120.3(20.4 \sim 338.3)$ & 0.510 \\
\hline Post-CRT PLR & $192.5(44.7 \sim 353.1)$ & $249.6(40.5 \sim 526.7)$ & 0.001 \\
\hline Change of PLR & $0.49(-.79 \sim 6.10)$ & $0.99(-0.06 \sim 5.61)$ & 0.001 \\
\hline
\end{tabular}

Values in parentheses are percentages unless indicated otherwise. MSS: Microsatellite stability or low-degree microsatellite instability; MSI: High-degree microsatellite instability; CEA: carcinoembryonic antigen; CRT: chemoradiotherapy; NLR: neutrophil to lymphocyte ratio; PLR: platelet to lymphocyte ratio. 
Table III. Survival analysis.

\begin{tabular}{|c|c|c|c|c|c|c|c|c|}
\hline \multirow[t]{2}{*}{ Factor } & \multirow[t]{2}{*}{ Factor } & \multirow[t]{2}{*}{$\mathrm{N}$} & \multicolumn{3}{|c|}{ OS } & \multicolumn{3}{|c|}{ DFS } \\
\hline & & & $5 \mathrm{yr}$ & $p$-Value* & $\mathrm{HR}^{\dagger}, 95 \% \mathrm{CI}$ & $5 \mathrm{yr}$ & $p$-Value* & $\mathrm{HR}^{\dagger}, 95 \% \mathrm{CI}$ \\
\hline \multirow[t]{2}{*}{ Gender } & Female & 149 & 86.5 & 0.713 & - & 73.7 & 0.595 & - \\
\hline & Male & 400 & 87.4 & & & 72.9 & & \\
\hline \multirow[t]{2}{*}{ Age } & $\leq 60$ & 261 & 92.1 & 0.067 & - & 76.3 & 0.202 & - \\
\hline & $>60$ & 288 & 83.2 & & & 70.3 & & \\
\hline \multirow[t]{2}{*}{$\mathrm{AV}$} & $>5 \mathrm{~cm}$ & 238 & 88.7 & 0.481 & - & 75.3 & 0.937 & - \\
\hline & $\leq 5 \mathrm{~cm}$ & 311 & 86.5 & & & 71.6 & & \\
\hline \multirow[t]{2}{*}{$\mathrm{cT}$} & $\mathrm{T} 1-2$ & 26 & 95.8 & 0.144 & - & 90.1 & 0.116 & - \\
\hline & T3-4 & 523 & 86.9 & & & 72.2 & & \\
\hline \multirow{2}{*}{$\begin{array}{l}\text { Clinical node } \\
\text { positive }\end{array}$} & No & 78 & 91.7 & 0.389 & - & 83.1 & 0.059 & - \\
\hline & Yes & 471 & 96.7 & & & 71.4 & & \\
\hline \multirow[t]{2}{*}{ Pre-treatment CEA } & $\leq 5.0$ & 388 & 88.9 & 0.054 & 1.376 & 76.8 & 0.014 & 1.407 \\
\hline & $>5.0$ & 161 & 83.8 & & $(0.895-2.145)$ & 64.1 & & $(0.991-1.979)$ \\
\hline \multirow{3}{*}{$\begin{array}{l}\text { Tumor regression } \\
\text { (Dworak grade) }\end{array}$} & & & & & & & & \\
\hline & $1-2$ & 471 & 86.5 & 0.067 & - & 72.2 & 0.162 & - \\
\hline & $3-4$ & 78 & 95.1 & & & 78.5 & & \\
\hline \multirow[t]{2}{*}{ Resection margin } & Negative & 522 & 88.4 & 0.002 & 1.907 & 74.3 & 0.002 & 1.632 \\
\hline & Positive & 27 & 65.4 & & $(0.899-4.042)$ & 48.4 & & $(0.886-3.004)$ \\
\hline \multirow[t]{2}{*}{ урт } & $0-2$ & 201 & 91.1 & 0.018 & 1.135 & 77.9 & 0.004 & 1.135 \\
\hline & $3-4$ & 342 & 85.4 & & $(0.865-1.488)$ & 70.3 & & $(0.865-1.488)$ \\
\hline \multirow[t]{2}{*}{ ypN } & 0 & 352 & 91.3 & $<0.001$ & 2.024 & 78.9 & $<0.001$ & 2.031 \\
\hline & $1-2$ & 195 & 73.9 & & $(1.273-3.219)$ & 55.0 & & $(1.413-2.918)$ \\
\hline \multirow[t]{2}{*}{ LI } & No & 485 & 87.9 & 0.321 & - & 73.6 & 0.664 & - \\
\hline & Yes & 64 & 83.3 & & & 70.1 & & \\
\hline \multirow[t]{2}{*}{ VI } & No & 510 & 88.2 & 0.087 & - & 73.7 & 0.202 & - \\
\hline & Yes & 48 & 78.2 & & & 66.3 & & \\
\hline \multirow[t]{2}{*}{ PNI } & No & 425 & 90.5 & 0.001 & 1.672 & 76.3 & $<0.001$ & 1.597 \\
\hline & Yes & 124 & 75.7 & & $(1.052-2.658)$ & 62.1 & & $(1.103-2.314)$ \\
\hline \multirow[t]{2}{*}{ MSI } & MSS or MSI-L & 512 & 88.0 & 0.911 & - & 72.9 & 0.847 & - \\
\hline & MSI-H & 37 & 79.6 & & & 76.4 & & \\
\hline \multirow[t]{2}{*}{ Pre-CRT NLR } & $\leq 2.0$ & 293 & 86.3 & 0.572 & - & 73.0 & 0.516 & - \\
\hline & $>2.0$ & 254 & 83.2 & & & 71.4 & & \\
\hline \multirow[t]{2}{*}{ Post-CRT NLR } & $\leq 2.9$ & 272 & 89.7 & 0.652 & - & 73.7 & 0.977 & - \\
\hline & $>2.9$ & 277 & 85.1 & & & 71.5 & & \\
\hline \multirow[t]{2}{*}{ Change of NLR } & $\leq 0.46$ & 276 & 88.7 & 0.460 & - & 75.2 & 0.160 & - \\
\hline & $>0.46$ & 23 & 86.1 & & & 75.9 & & \\
\hline \multirow[t]{2}{*}{ Pre-CRT PLR } & $\leq 130.7$ & 274 & 89.3 & 0.472 & - & 72.8 & 0.981 & - \\
\hline & $>130.7$ & 275 & 85.5 & & & 73.5 & & \\
\hline Post-CRT PLR & $\leq 198.8$ & 272 & 88.8 & 0.528 & - & 74.0 & 0.463 & - \\
\hline & $>198.8$ & 277 & 85.8 & & & 72.3 & & \\
\hline Change of PLR & $\leq 0.52$ & 276 & 89.0 & 0.834 & - & 74.2 & 0.515 & - \\
\hline & $>0.52$ & 273 & 85.7 & & & 72.1 & & \\
\hline
\end{tabular}

${ }^{*}$ Log-rank test; ${ }^{\dagger}$ Cox regression analysis; HR: hazard ratio; CI: confidence interval; OS: overall survival; DFS: disease-free survival; AV: anal verge; CEA: carcinoembryonic antigen; LI: lymphatic invasion; VI: venous invasion; PNI: perineural invasion; MSI: microsatellite instability; MSI-H: high-degree microsatellite instability; MSI-L: low-degree microsatellite instability; MSS: microsatellite stability; CRT: chemoradiotherapy; NLR: neutrophil-to-lymphocyte ratio; PLR: platelet-to-lymphocyte ratio.

microenvironment (7). Furthermore, MSI in colorectal cancer has been found to be predictive of poor response to 5fluorouracil based chemotherapy and better response to immunotherapy such as checkpoint inhibitors $(8,9)$. As an immunogenic tumor, the anti-tumor immunity and protumoral inflammation microenvironment plays an essential role in immunotherapy in colorectal cancer with MSI (7-9).
Based on previous findings, we hypothesized that MSI status could affect the immunologic status in rectal cancer during CRT and might lead to changes in the inflammatory markers and its prognosis. Although neoadjuvant CRT is part of the standard care in rectal cancer, it has not been studied whether MSI as a representative of microenvironments related to the dynamics and prognostic value of 
inflammatory markers. Thus, in the present study, we aimed to analyze the correlation between the MSI and inflammatory markers during neoadjuvant CRT in rectal cancer and its influence on prognosis.

\section{Patients and Methods}

Patients. The present study was approved by the Institutional Ethical Review Board of the Seoul National University Bundang Hospital (IRB no. B-1807-478-106) and Seoul National University Hospital (IRB no. J-2001-054-1093). We retrospectively reviewed the medical records of patients with rectal cancer who underwent neoadjuvant CRT followed by surgery in the two affiliated tertiary academic hospitals. The time of treatment for rectal cancer was from January 2004 to August 2015 in Seoul National University Bundang Hospital and from January 2004 to December 2011 in Seoul National University Hospital. Inclusion criteria were as follows: (i) Pathologically confirmed primary rectal cancer; (ii) neoadjuvant CRT followed by surgery; (iii) serial complete blood count (CBC) examination throughout CRT; (iv) immunologically competent before and during CRT, including absolute neutrophil count $(\mathrm{ANC})>1,000 / \mu 1$, white blood cell count (WBC) before and during CRT, including absolute neutrophil count $($ ANC $)>1,000 / \mu l$, white blood cell count (WBC) between 4,000 and 10,000 $\mu \mathrm{l}$; (v) negative for hepatitis $B$ virus antigen, anti-hepatitis $C$ virus, antihuman immunodeficiency virus, and venereal disease research laboratory results before CRT. We excluded patients showing complete regression in the surgical specimen, because the MSI could not be evaluated. Patients were staged according to the classification system of the American Joint Committee on Cancer (7th edition) (10). The number of total eligible patients meeting the inclusion criteria was 549 .

Treatment. All patients underwent clinical examination, including digital rectal examination, routine laboratory tests with carcinoembryonic antigen (CEA) level, and colonoscopic examination, computed tomography of the chest and abdomenpelvis, and rectal magnetic resonance imaging. The rectal cancer was histologically confirmed before neoadjuvant CRT.

For neoadjuvant CRT, the median radiation dose was 50.4 Gy (range $=50.4-55.8 \mathrm{~Gy}$ ) with conventional fractionations. Patients were mainly treated with the combination of chemotherapy with intravenous 5-fluorouracil or capecitabine throughout the radiation period. Following neoadjuvant CRT, all patients underwent curative radical surgery 4 to 8 weeks after neoadjuvant CRT.

MSI status determination. The DNA was extracted from each paraffin block after deparaffinization. To evaluate the MSI status, five quasimonomorphic mononucleotide markers (BAT-25, BAT-26, NR-21, NR-24, and MONO-27) were coamplified in a single polymerase chain reaction $(11,12)$. Samples with instability at two or more of the five markers were classified as high-degree microsatellite instability (MSI-H). In contrast, those with instability at one and no marker were classified as low-degree microsatellite instability (MSI-L) and microsatellite stability (MSS), respectively (11).

Blood test. CBC was performed throughout CRT. Laboratory index values, including neutrophil counts, lymphocyte counts, and CEA, were obtained for each patient before CRT (pre-CRT), and 4-6 weeks after CRT (post-CRT). NLR and PLR was calculated as the
Table IV. Subgroup analysis according to microsatellite instability.

\begin{tabular}{|c|c|c|c|c|c|}
\hline \multicolumn{6}{|c|}{ Microsatellite instability, high-grade } \\
\hline \multirow[t]{2}{*}{ Factor } & \multirow[t]{2}{*}{ Factor } & \multicolumn{2}{|c|}{ OS } & \multicolumn{2}{|c|}{ DFS } \\
\hline & & $5 \mathrm{yr}$ & $p$-Value & $5 \mathrm{yr}$ & $p$-Value \\
\hline \multirow[t]{2}{*}{ Pre-CRT NLR } & $\leq 2.0$ & 93.3 & 0.049 & 91.7 & 0.020 \\
\hline & $>2.0$ & 65.4 & & 65.3 & \\
\hline \multirow[t]{2}{*}{ Post-CRT NLR } & $\leq 2.9$ & 90.9 & 0.069 & 90.0 & 0.091 \\
\hline & $>2.9$ & 74.5 & & 73.0 & \\
\hline \multirow[t]{2}{*}{ Change of NLR } & $\leq 0.46$ & 92.3 & 0.133 & 91.7 & 0.137 \\
\hline & $>0.46$ & 70.8 & & 68.5 & \\
\hline \multirow[t]{2}{*}{ Pre-CRT PLR } & $\leq 130.7$ & 88.2 & 0.043 & 85.9 & 0.047 \\
\hline & $>130.7$ & 70.9 & & 68.2 & \\
\hline \multirow[t]{2}{*}{ Post-CRT PLR } & $\leq 198.8$ & 83.3 & 0.773 & 83.3 & 0.980 \\
\hline & $>198.8$ & 79.6 & & 78.1 & \\
\hline \multirow[t]{2}{*}{ Change of PLR } & $\leq 0.52$ & 83.3 & 0.754 & 83.3 & 0.953 \\
\hline & $>0.52$ & 79.5 & & 77.4 & \\
\hline
\end{tabular}

Microsatellite stability or instability, low-grade

\begin{tabular}{lccccc}
\hline Factor & Factor & OS & \multicolumn{3}{c}{ DFS } \\
\hline Pre-CRT NLR & $\leq 2.0$ & 73.5 & 0.788 & 73.5 & 0.853 \\
& $>2.0$ & 72.4 & & 72.4 & \\
Post-CRT NLR & $\leq 2.9$ & 72.5 & 0.898 & 72.5 & 0.587 \\
& $>2.9$ & 73.4 & & 73.4 & \\
Change of NLR & $\leq 0.46$ & 74.1 & 0.715 & 74.1 & 0.319 \\
& $>0.46$ & 71.6 & & 71.6 & \\
Pre-CRT PLR & $\leq 130.7$ & 73.6 & 0.231 & 73.6 & 0.558 \\
& $>130.7$ & 72.3 & & 72.3 & \\
Post-CRT PLR & $\leq 198.8$ & 73.7 & 0.527 & 73.7 & 0.452 \\
& $>198.8$ & 72.0 & & 72.0 & \\
Change of PLR & $\leq 0.52$ & 73.5 & 0.960 & 73.5 & 0.666 \\
& $>0.52$ & 72.3 & & 72.3 & \\
\hline
\end{tabular}

CRT: Chemoradiotherapy; NLR: Neutrophil-to-lymphocyte ratio; PLR: platelet-to-lymphocyte ratio; OS: overall survival; DFS: disease-free survival.

ratio of the neutrophil count and of the platelet count divided by the lymphocyte count. The ratio of change in NLR (cNLR) and PLR (cPLR) was calculated using the following formula: $\mathrm{cNLR}=$ (postCRT NLR-pre-CRT NLR)/pre-CRT NLR, cPLR=(post-CRT NLRpre-CRT NLR)/pre-CRT NLR.

Statistical analysis. The chi-square test was applied for categorical variables, and Student's $t$-test was applied for continuous variables. Patients were divided into groups based on the median index value of inflammatory markers. Overall survival (OS) and progressionfree survival (DFS) were calculated as the interval from the first date of treatment to the date of death and to the date that progression was detected, respectively. Survival curves were generated using the Kaplan-Meier method, and univariate survival comparison was performed using the log-rank test. Multivariate survival comparison was performed using the Cox regression analysis. A value of $p<0.050$ was considered statistically significant. Analyses were performed using SPSS version 18 (SPSS Inc., Chicago, IL, USA). 


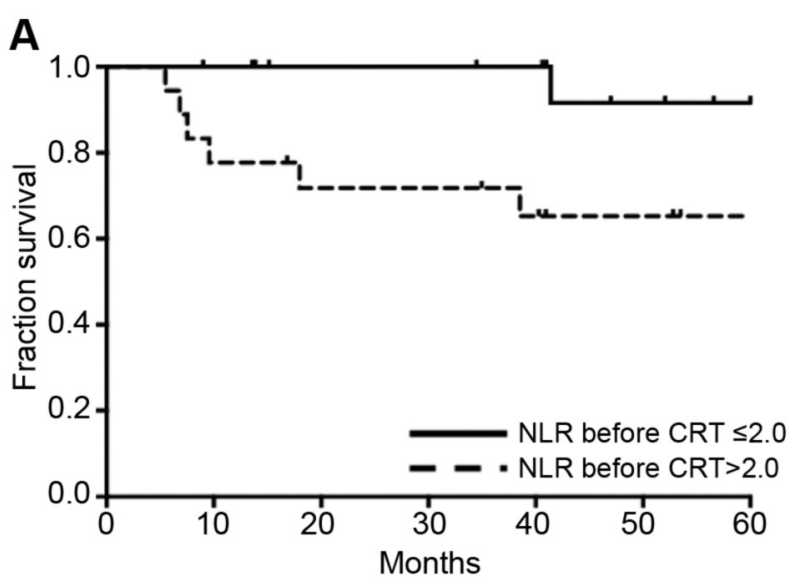

Figure 1. Disease-free survival according to inflammatory markers.

\section{Results}

The relationship between MSI and inflammatory markers. Patient characteristics and NLR profiles are detailed in Table I. The proportions of MSI-H and MSI-L/MSS were $6.7 \%$ $(n=37)$ and $93.3 \%(n=512)$, respectively. Compared with MSI-L/MSS (Table II), MSI-H patients had significantly higher post-CRT NLR, cNLR, post-CRT PLR, cPLR ( $p=0.004,0.011,0.00$, and 0.001 , respectively), and a nonsignificant trend for lower tumor location and better tumor regression ( $p=0.060$ and 0.089 , respectively). Otherwise, no statistical difference between the two groups was observed in clinical factors, including tumor regression grade $(p=0.360$ and 0.720 , respectively).

Analysis of prognostic factors. The analysis of survival outcomes is shown in Table III. Resection margin (RM), ypT, ypN, and perineural invasion (PNI) were significant prognostic factors that correlated with OS $(p=0.002,0.018$, $<0.001$, and 0.001, respectively). Pre-treatment CEA, RM, ypT, ypN, and PNI were significant prognostic factors for DFS $(p=0.014,0.002,0.004,<0.001$, and $<0.001$, respectively). MSI status and inflammation markers were not significantly related to survival and disease control rate. In multivariate analysis, ypN and perineural invasion (PNI) are independently significant factors for OS and DFS.

Different prognostic effects of NLR according to MSI status. In the subgroup of MSI-H, the increase of pre-CRT NLR and PLR was significantly correlated with poor OS and DFS (Table IV and Figure 1). However, in patients with MSIL/MSS, NLR and PLR had no prognostic effect on all clinical endpoints. The distribution of significant factors in prognostic analysis was compared between patient groups dichotomized into pre-CRT NLR and PLR. Pre-treatment

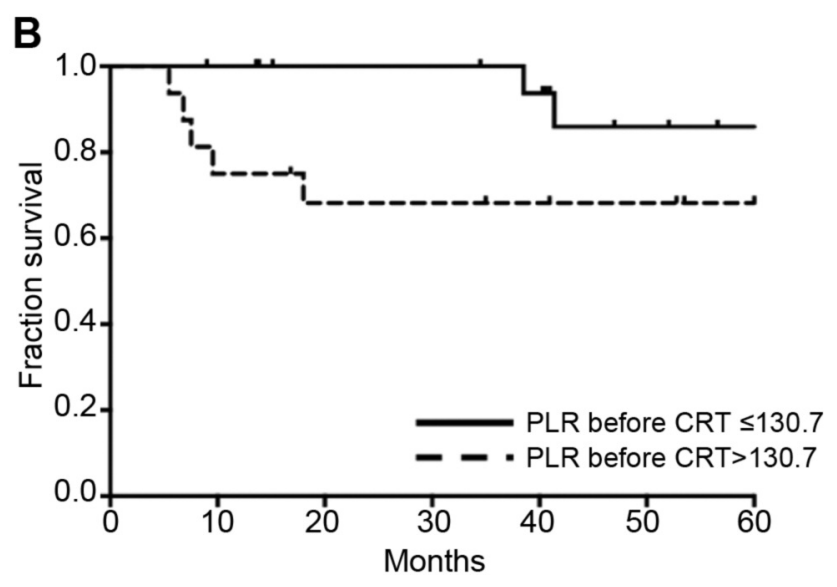

CEA, RM, ypT, ypN, and PNI, which were found to be significant factors in the prognostic analysis, were not statistically different between pre-CRT NLR and PLR.

\section{Discussion}

In this study, MSI-H patients demonstrated a significant increase in NLR and PLR during CRT and high levels of NLR and PLR after CRT, whereas the baselines of inflammatory markers were not different according to MSI status. A previous study has also shown that baseline NLR in colorectal cancer was not significantly different according to MSI status (13). However, to the best of our knowledge, this is the first report to show the relationship between the change of inflammatory markers and MSI during neoadjuvant CRT for rectal cancer. Among the different molecular subtypes of colorectal cancer, the MIS-immune type tends to have hyper-mutation and be vulnerable to immune infiltration and inflammation (7). The response of rectal cancer to CRT can depend on the change of the immunologic and inflammatory microenvironment during CRT (14-16). The systemic inflammatory response can cause alterations in circulating leukocytes, especially neutrophilia and thrombophilia with a lymphopenia $(17,18)$, which can be calculated as NLR and PLR. Therefore, our findings indicate that changes in NLR and PLR might reflect the dynamics of systemic inflammation and immune response induced by CRT, especially in patients with MSI.

If the change in inflammatory markers can reflect the degree of systemic inflammation and immune response during CRT, the clinical utility of inflammatory markers can be one of the predictive or prognostic markers of the response to immunologic agents for rectal cancer. Programmed cell death 1-blocking antibodies have improved survival in patients with metastatic colorectal cancer with 
MSI-H (9). However, there is weak background evidence regarding the primary treatment of rectal cancer with immunologic agents. Moreover, the big challenge of immunotherapy is the absence of predictive markers for a response, while only $10-20 \%$ of patients respond to immunotherapy even in immunogenic tumors $(1,5,6)$. The close relationship between the change in inflammatory markers during CRT and MSI in our study indicates that inflammatory markers may reflect the immunologic change induced by CRT. Previous studies have also confirmed that inflammatory markers could be used as predictive markers of the response to immunogenic agents in immunogenic tumors such as renal cell carcinoma (5), and melanoma (6).

The prognostic effect of MSI and inflammatory markers after CRT in rectal cancer is controversial. Previous studies about the difference in clinical outcomes, according to MSI, have shown conflicting results (19-22). Also, only a limited number of studies have reported inconsistent data on the potential role of inflammatory markers as a predictive factor for survival $(2,23-26)$. We could not find any significant prognostic effect of MSI or inflammatory markers in the rectal cancer patients. Increased NLR or PLR caused by neutrophilia, thrombophilia or lymphopenia denotes the enhanced accumulation of immune-suppressive myeloid cells and suppression of anti-tumor immunity. Our finding indicating that inflammatory markers had a robust prognostic effect only in MSI-H tumors support the conclusion that the clinical impact of inflammatory markers can be augmented in the immunogenic tumor such as MSI-H (27). Howard et al. have also confirmed that the prognostic value of NLR is heterogeneous among 18 cancer types and has the most significant effect on prognosis in the melanoma, one of the representative immunogenic tumors (28). Therefore, to refine the clinical utility of NLR from the previous inconsistent studies, research should focus on the role of inflammatory markers in the context of immunogenic tumors and immunotherapy.

The small sample size of MSI-H was the major limitation of this study. However, the incidence of MSI-H is infrequent, only about $2-8 \%$ in rectal cancer $(19-22,29)$. Among the clinical studies dealing with this subject $(19,21,22,29)$, our study included the largest number of MIS-H patients. Although Hassan et al. (20) have collected 636 MSI-positive patients through the National Cancer Database, they did not discriminate MSI-H against MSI-L, which is immunologically and clinically similar to MSS. Moreover, our cohort comprised homogeneous patients treated at two affiliated hospitals with consistent treatment guidelines regarding CRT, surgery and pathological review techniques. However, our study did not address whether MSI and inflammatory markers can affect the immunologic response to the combined strategies of standard CRT and immunotherapy. This should be addressed in future studies
(30). Moreover, detailed analysis of the microenvironments and immune cells using specimens of rectal cancer can highlight the clinical value of inflammatory markers to predict the change between pro- and anti-tumoral immunity.

\section{Conclusion}

This study found a close correlation between inflammatory markers and MSI during CRT and its influence on prognosis. These findings suggest the potential role of inflammatory markers in assessing the immunologic microenvironments related to MSI and the immunologic response in rectal cancer.

\section{Conflicts of Interest}

The Authors declare that they have no competing interests regarding this study.

\section{Authors' Contributions}

JHL, EKC, JSK conceived of and designed the study. JHL, BK, CS, SK, HSL, and KL provided data. JHL and BK performed the statistical analysis. JHL, EKC, JSK drafted the manuscript. All Authors read and approved the final manuscript.

\section{References}

1 Weichselbaum RR, Liang H, Deng L and Fu YX: Radiotherapy and immunotherapy: a beneficial liaison? Nat Rev Clin Oncol 14: 365-379, 2017. PMID: 28094262. DOI: 10.1038/nrclinonc. 2016.211

2 Lee JH, Song C, Kang SB, Lee HS, Lee KW and Kim JS: Predicting pathological complete regression with haematological markers during neoadjuvant chemoradiotherapy for locally advanced rectal cancer. Anticancer Res 38: 6905-6910, 2018. PMID: 30504408. DOI: 10.21873/anticanres.13067

3 Cheng H, Luo G, Lu Y, Jin K, Guo M, Xu J, Long J, Liu L, Yu $\mathrm{X}$ and Liu C: The combination of systemic inflammation-based marker NLR and circulating regulatory $\mathrm{T}$ cells predicts the prognosis of resectable pancreatic cancer patients. Pancreatology 16: 1080-1084, 2016. PMID: 27665172. DOI: 10.1016/j.pan. 2016.09.007

4 Ohki S, Shibata M, Gonda K, Machida T, Shimura T, Nakamura I, Ohtake T, Koyama Y, Suzuki S, Ohto H and Takenoshita S: Circulating myeloid-derived suppressor cells are increased and correlate to immune suppression, inflammation and hypoproteinemia in patients with cancer. Oncol Rep 28: 453458, 2012. PMID: 22614133. DOI: 10.3892/or.2012.1812

5 Lalani A-KA, Xie W, Martini DJ, Steinharter JA, Norton CK, Krajewski KM, Duquette A, Bossé D, Bellmunt J and Allen EMV: Change in neutrophil-to-lymphocyte ratio (NLR) in response to immune checkpoint blockade for metastatic renal cell carcinoma. JI Immunother Cancer 6: 5, 2018. PMID: 29353553. DOI: $10.1186 / \mathrm{s} 40425-018-0315-0$

6 Capone M, Giannarelli D, Mallardo D, Madonna G, Festino L, Grimaldi AM, Vanella V, Simeone E, Paone M and Palmieri G: Baseline neutrophil-to-lymphocyte ratio (NLR) and derived NLR could predict overall survival in patients with advanced 
melanoma treated with nivolumab. J Immunother Cancer 6: 74, 2018. PMID: 30012216. DOI: 10.1186/s40425-018-0383-1

7 Guinney J, Dienstmann R, Wang X, Reyniès A de, Schlicker A, Soneson C, Marisa L, Roepman P, Nyamundanda G, Angelino P, Bot BM, Morris JS, Simon IM, Gerster S, Fessler E, Melo FDSE, Missiaglia E, Ramay H, Barras D, Homicsko K, Maru D, Manyam GC, Broom B, Boige V, Perez-Villamil B, Laderas T, Salazar R, Gray JW, Hanahan D, Tabernero J, Bernards R, Friend SH, Laurent-Puig P, Medema JP, Sadanandam A, Wessels L, Delorenzi M, Kopetz S, Vermeulen L and Tejpar S: The consensus molecular subtypes of colorectal cancer. Nat Med 21: nm.3967, 2015. PMID: 26457759. DOI: 10.1038/nm.3967

8 Ribic CM, Sargent DJ, Moore MJ, Thibodeau SN, French AJ, Goldberg RM, Hamilton SR, Laurent-Puig P, Gryfe R, Shepherd LE, Tu D, Redston M and Gallinger S: Tumor microsatelliteinstability status as a predictor of benefit from fluorouracil-based adjuvant chemotherapy for colon cancer. New Engl J Med 349: 247-257, 2003. PMID: 12867608. DOI: 10.1056/NEJMoa 022289

9 Le DT, Uram JN, Wang H, Bartlett BR, Kemberling H, Eyring AD, Skora AD, Luber BS, Azad NS, Laheru D, Biedrzycki B, Donehower RC, Zaheer A, Fisher GA, Crocenzi TS, Lee JJ, Duffy SM, Goldberg RM, Chapelle A de la, Koshiji M, Bhaijee F, Huebner T, Hruban RH, Wood LD, Cuka N, Pardoll DM, Papadopoulos N, Kinzler KW, Zhou S, Cornish TC, Taube JM, Anders RA, Eshleman JR, Vogelstein B and Diaz LA: PD-1 blockade in tumors with mismatch-repair deficiency. New Engl J Medicine 372: 2509-2520, 2015. PMID: 26028255. DOI: 10.1056/NEJMoa1500596

10 Edge SB, Byrd DR, Carducci MA, Compton CC, Fritz A and Greene F: AJCC cancer staging manual, 2010.

11 Patil DT, Bronner MP, Portier BP, Fraser CR, Plesec TP and Liu $\mathrm{X}$ : A five-marker panel in a multiplex PCR accurately detects microsatellite instability-high colorectal tumors without control DNA. Diagnostic Mol Pathology Am J Surg Pathology Part B 21: 127-133, 2012. PMID: 22847155. DOI: 10.1097/PDM. 0b013e3182461cc3

12 Laiho P, Launonen V, Lahermo P, Esteller M, Guo M, Herman JG, Mecklin JP, Järvinen H, Sistonen P, Kim K-M, Shibata D, Houlston RS and Aaltonen LA: Low-level microsatellite instability in most colorectal carcinomas. Cancer Res 62: 11661170, 2002. PMID: 11861399.

13 Rashtak S, Ruan X, Druliner BR, Liu H, Therneau T, Mouchli $\mathrm{M}$ and Boardman LA: Peripheral neutrophil to lymphocyte ratio improves prognostication in colon cancer. Clin Colorectal Cancer 16: 115-123, 2017. PMID: 28365393. DOI: 10.1016/j. clcc.2017.01.008

14 Lim YJ, Koh J, Kim S, Jeon SR, Chie EK, Kim K, Kang GH, Han SW, Kim T-Y, Jeong SY, Park KJ and Wu HG: Chemoradiation-induced alteration of programmed death-ligand 1 and CD8+tumor-infiltrating lymphocytes identified patients with poor prognosis in rectal cancer: A matched comparison analysis. Int J Radiat Oncol Biology Phys 99: 1216-1224, 2017. PMID: 29165286. DOI: 10.1016/j.ijrobp.2017.07.004

15 Lee JH, Chie EK, Jeong SY, Kim TY, Kim DY, Kim TH, Kim SY, Baek JY, Chang HJ, Kim MJ, Park SC, Oh JH, Kim SH, Lee JH, Choi DH, Park HC, Kang S-B and Kim JS: Redefining the positive circumferential resection margin by incorporating preoperative chemoradiotherapy treatment response in locally advanced rectal cancer: a multicenter validation study. Cancer
Res Treat 50: 506-517, 2018. PMID: 28546522. DOI: 10.4143/ crt.2016.607

16 Lee JH, Chie EK, Kim K, Jeong SY, Park KJ, Park JG, Kang GH, Han SW, Oh DY, Im SA, Kim TY, Bang YJ and Ha SW: The influence of the treatment response on the impact of resection margin status after preoperative chemoradiotherapy in locally advanced rectal cancer. BMC Cancer 13: 576, 2013. PMID: 24304825. DOI: 10.1186/1471-2407-13-576

17 Epstein FH, Gabay C and Kushner I: Acute-phase proteins and other systemic responses to inflammation. New Engl J Med 340: 448-454, 1999. PMID: 9971870. DOI: 10.1056/NEJM19990 2113400607

18 Imtiaz F, Shafique K, Mirza SS, Ayoob Z, Vart P and Rao S: Neutrophil lymphocyte ratio as a measure of systemic inflammation in prevalent chronic diseases in Asian population. Int Arch Med 5: 2, 2012. PMID: 22281066. DOI: 10.1186/17557682-5-2

19 Acar T, Acar N, Kamer E, Tekindal MA, Cengiz F, Kar H, Atahan K and Haciyanli M: Do microsatellite instability (MSI) and deficient mismatch repair (dMMR) affect the pathologic complete response $(\mathrm{pCR})$ in patients with rectal cancer who received neoadjuvant treatment? Updates Surg 72(1): 73-82, 2020. PMID: 31863279. DOI: 10.1007/s13304-019-00697-2

20 Hasan S, Renz P, Wegner RE, Finley G, Raj M, Monga D, McCormick $J$ and Kirichenko A: Microsatellite instability (MSI) as an independent predictor of pathologic complete response (PCR) in locally advanced rectal cancer. Ann Surg, 2018. PMID: 30216221. DOI: 10.1097/SLA.0000000000 003051

21 Charara M, Edmonston TB, Burkholder S, Walters R, Anne P, Mitchell E, Fry R, Boman B, Rose D, Fishel R, Curran W and Palazzo J: Microsatellite status and cell cycle associated markers in rectal cancer patients undergoing a combined regimen of 5FU and CPT-11 chemotherapy and radiotherapy. Anticancer Res 24: 3161-3167, 2004. PMID: 15510606.

22 Samowitz WS, Curtin K, Wolff RK, Tripp SR, Caan BJ and Slattery ML: Microsatellite instability and survival in rectal cancer. Cancer Causes Control 20: 1763-1768, 2009. PMID: 19669908. DOI: 10.1007/s10552-009-9410-3

23 Carruthers R, Tho LM, Brown J, Kakumanu S, McCartney E and McDonald AC: Systemic inflammatory response is a predictor of outcome in patients undergoing preoperative chemoradiation for locally advanced rectal cancer. Colorectal Dis 14: e701-707, 2012. PMID: 22731833. DOI: 10.1111/j.14631318.2012.03147.x

24 Yang J, Xu H, Guo X, Zhang J, Ye X, Yang Y and Ma X: Pretreatment inflammatory indexes as prognostic predictors for survival in colorectal cancer patients receiving neoadjuvant chemoradiotherapy. Sci Rep 8: 3044, 2018. PMID: 29445100. DOI: $10.1038 / \mathrm{s} 41598-018-21093-7$

25 Lee IH, Hwang S, Lee SJ, Kang BW, Baek D, Kim HJ, Park SY, Park JS, Choi GS, Kim JC, Cho SH and Kim JG: Systemic inflammatory response after preoperative chemoradiotherapy can affect oncologic outcomes in locally advanced rectal cancer. Anticancer Res 37: 1459-1466, 2017. PMID: 28314318. DOI: 10.21873/anticanres. 11470

26 Petrelli F, Ghidini M, Cabiddu M, Pezzica E, Corti D, Turati L, Costanzo A, Varricchio A, Ghidini A, Barni S, Tomasello: Review: Microsatellite instability and survival in stage II colorectal cancer: A systematic review and meta-analysis. 
Anticancer Res 39: 6431-6441, 2019. PMID: 31810907. DOI: 10.21873/anticanres. 13857

27 Su P, Dong Y, Shi Y and He L: Prognostic significance of neutrophil-to-lymphocyte ratio in rectal cancer: a meta-analysis. Oncotargets Ther 9: 3127-3134, 2016. PMID: 27307753. DOI: 10.2147/OTT.S103031

28 Howard R, Kanetsky PA and Egan KM: Heterogeneity in prognostic value of the neutrophil-to-lymphocyte ratio: a metaanalysis. MedRxiv: 19011387, 2019. DOI: 10.1101/19011387

29 Hong SP, Min BS, Kim TI, Cheon JH, Kim NK, Kim H and Kim WH: The differential impact of microsatellite instability as a marker of prognosis and tumour response between colon cancer and rectal cancer. Eur J Cancer 48: 1235-1243, 2012. PMID: 22071131. DOI: $10.1016 /$ j.ejca.2011.10.005

30 Zhang J, Cai J, Deng Y and Wang H: Complete response in patients with locally advanced rectal cancer after neoadjuvant treatment with nivolumab. Oncoimmunology 8: 1663108, 2019. PMID: 31741760. DOI: 10.1080/2162402X.2019.1663108

Received March 21, 2020

Revised March 31, 2020

Accepted April 2, 2020 